\title{
Switching from static to adaptable and dynamic building envelopes: A paradigm shift for the energy efficiency in buildings
}

\author{
Marco Perino* and Valentina Serra \\ Department of Energy, Politecnico di Torino, Corso Duca degli Abruzzi 24, Torino, Italy
}

\begin{abstract}
The key role of the building envelope in attaining building energy efficiency and satisfactory indoor comfort has long been established. Nevertheless, until recent times, all efforts and attention have mainly been focused on increasing and optimizing the thermal insulation of the envelope components. This strategy was a winning approach for a long time, but its limitations became obvious when users and designers started to consider the overall energy demand of a building and started to aim for Zero Energy Building (ZEB) or nearly ZEB goals. New and more revolutionary concepts and technologies needed to be developed to satisfy such challenging requirements. The potential benefits of this technological development are relevant since the building envelope plays a key role in controlling the energy and mass flows from outdoors to indoors (and vice versa) and, moreover, the facades offer a significant opportunity for solar energy exploitation. Several researches have demonstrated that the limitation of the existing facades could be overcome only by switching from 'static' to 'responsive' and 'dynamic' systems, such as Multifunctional Facade Modules (MFMs) and Responsive Building Elements (RBE). These components are able to continuously and pro-actively react to outdoor and indoor environment conditions and facilitate and enhance the exploitation of renewable and low exergy sources. In order to reduce the energy demand, to maximize the indoor comfort conditions and to produce energy at the site, these almost 'self-sufficient', or even 'positive energy' building skins frequently incorporate different technologies and are functionally connected to other building services and installations. An overview of the technological evolution of the building envelope that has taken place, ranging from traditional components to the innovative skins, will be given in this paper, while focusing on the different approaches that have characterized this development. Examples of innovative solutions for responsive and dynamic components and the future trends of development will also be described.
\end{abstract}

Keywords: Adaptive building envelope, responsive building envelope, multifunctional facade, Phase Change Materials (PCMs), thermotropic glazing, advanced integrated facades

\section{Introduction}

Since their origins human beings frantically sought for confined spaces within which they could be safe and comfortable. If safety and security were the earliest concern, it was soon realized that a confined space could also be an effective measure to create a thermally comfortable environment. To enhance such function, the attention was focused on the building envelope, perceiving this construction element as a set of sub-systems and/or components which was used to separate the outdoor

*Corresponding author: Marco Perino, Tel.: +39 011 0904423; Fax: +39 011 0904499; E-mail: marco.perino@polito.it. 


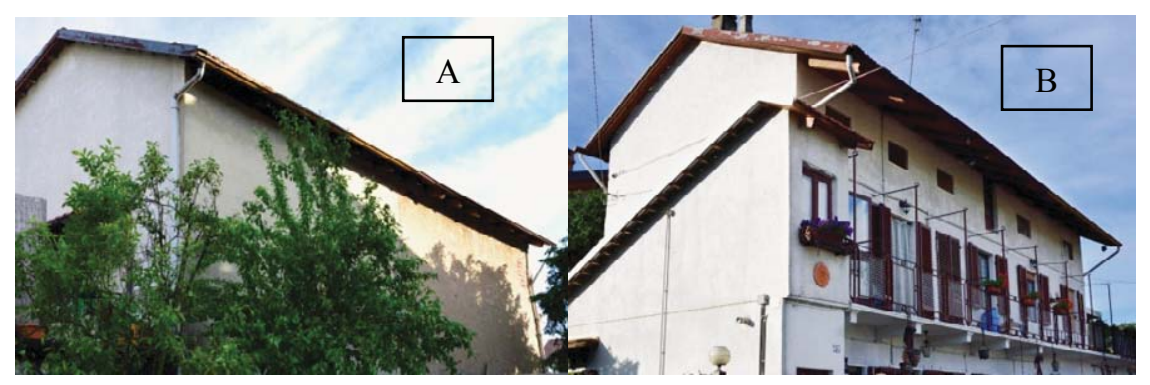

Fig. 1. Typical example of building envelope optimization in traditional architecture, based on the classical approach of the 'energy conservation' $-\mathrm{HHD}=2894^{\circ} \mathrm{C} \cdot \mathrm{d}$, winter design temperature $-8^{\circ} \mathrm{C}$, summer design temperature $32^{\circ} \mathrm{C}, \mathrm{CDD}=386^{\circ} \mathrm{C} \cdot \mathrm{d}$ - (ASHRAE, 2013) (A: north exposition; B: south exposition).

from the indoor. The underlying and common idea was therefore that of creating a shield, able to protect the built environment - which was climatised - from the weather, and from the strains of an external climate, which was considered to be hostile. As a result, the ultimate goal of designers and engineers was, and has been for centuries, to optimize the 'separation effect'. This was typically achieved by improving properties like those of - broadly speaking - 'insulation', 'tightness' and 'waterproofing' of the building envelope components.

The shape and the structure assumed by the building facades has been the mirror of such conception. Moreover, keeping the indoor air temperature at a sufficient level in the cold season was assumed to be the unique relevant requirement for assuring a proper IEQ (Indoor Environmental Quality), while air-conditioning in the summer period, artificial lighting and plug-loads ${ }^{1}$ were not of concern, either because they were deemed optional gimmicks or because the energy demand related to them was comparably lower. Such vision and concepts supported the assumption that the energy efficiency in buildings could be achieved just by minimizing the heat transmission losses through the building envelope and maximizing the free gains. These were the foundations of the so-called 'Energy conservation approach' (Goia, 2013) that has driven the building and facade design and development until recently.

As a consequence, in the past - at least in the industrialized countries - the building envelope assumed the shape of massive opaque walls with only few and small transparent openings. The difficulty of finding suitable energy sources, to make them available on site and to convert them through efficient processes, also led to optimize the building envelope in relation to the opportunities offered by the local climate conditions. These characteristics are easy to recognize just looking at the traditional architectures, where the envelope was designed according to the exposition, adopting different ratios of transparent and opaque surfaces (see the example in Figure 1 - maximization of the solar gains, by means of windows on the southern walls, and of the thermal insulation, using thick masonry walls, on the northern side).

Such design and construction philosophy allowed, through the centuries, to satisfy the requirements of mechanical resistance and those of a basic thermal protection. The presence of an opaque structure with a high thermal mass could provide an effective thermal storage, and the thermal resistance even though it was not optimal - was at least adequate to the indoor environmental quality that was expected by the occupants at that time, especially if compared to the very bad performance

\footnotetext{
${ }^{1}$ The plug-loads are the loads deriving from electric devices such as computers, televisions, electric appliance etc.
} 
that the available transparent components back then could provide. In this period, the technological evolution developed along the improvement of the construction techniques and of the properties of the materials, but it stayed crystallized on the energy conservation approach.

Indeed, these innovations, the use of new materials (steel, concrete, glass etc.) and the improvement of the design procedures allowed to 'disembody' the surfaces of the building envelope and to split the function of structural resistance from the others (like e.g. thermal, protective, aesthetic). The facades of traditional buildings - solid, compact, massive - can now be made lighter by introducing 'airy' and transparent elements, whose extension grew more and more, to such an extent of replacing - in certain cases - almost completely the opaque surfaces.

An era of enthusiasm and confidence about the technology started, which was inspired by the cultural movement of modernism and supported by the availability of reliable and relatively energy efficient conversion systems and of energy vectors at a rather low cost. The combination of all these favourable factors led to the development of projects where the local climatic conditions were no longer taken into account in a proper way. Many designers and architects started to focus the attention mainly on formal and aesthetic issues, rather than on energy implications and comfort conditions, and to uncritically follow the style proposed by the international 'trend setter' architects. As a consequence, a flourishing of buildings in which the poor performance of the facades was counterbalanced by the installation of oversized HVAC systems took place. These designs were invariably characterized by an unacceptable high energy consumption and disappointing indoor environmental quality.

A stigmatic example is represented by the fashion of using large glazed surfaces having a size that is excessive with respect to the need for daylighting. Such facade configuration gives origin to significant transmission heat losses during the winter and to huge solar heat gains in the summer period. The obvious, and just apparent, remedy of installing oversized HVAC systems has the only effect of counterbalancing, at least under the mere energy balance point of view, the excessive free gains, but is not capable of solving the local discomfort problems in a satisfactory way (e.g. draft risk, noise, radiant asymmetry). This is due to both excessively high and low radiant temperatures, and to the draft risk consequent to the need of introducing large flow rates of conditioned air (required to counterbalance the 'massive' thermal loads). The energy crisis in the early seventies, the increasing cost of the energy, a growing consciousness towards environmental problems and, last but not least, the dissatisfaction of the occupants (who were living in nice looking but not so comfortable buildings) represented the boost towards the next steps of the evolution.

The first law on the energy conservation in buildings dates back to the early 1970s. For the first time, and practically in the whole industrialized world, minimum requirements on the thermo-physical performance of opaque and transparent building envelope components were set. However, also this new phase of development was driven by the 'energy conservation approach' and the attention was focused, almost completely, on measures aimed at limiting the energy demand for space heating through the reduction of the transmission and ventilation losses - and to maximize the solar free gains. From a technological point of view that meant: increasing the thickness of the insulation layers in the opaque walls, improving the thermal transmittance of the glazing and the air-tightness of the buildings, installing heat recovery units and enhancing the harvesting of the solar energy (either 'passively', through transparent building envelope components and/or solar greenhouses, or 'actively', by means of solar thermal systems). Proofs of such conventional wisdom are the studies done at the MIT in Boston (Hottel, 1989), during that period.

The facades that today 'dress' the majority of the buildings are the result of such technological evolution and even if the awareness for the energy sustainability and Indoor Environmental Quality 
(IEQ) has grown, still many designers pay little attention to the 'optimization' of the building envelope with respect to the needs of the indoor environment, to the exposition and to the climatic context, as one can see in Figure 2.

Certainly, in the course of 20-30 years, the widespread and continuous application of this strategy led to a drastic reduction of the energy demand for space heating and allowed to cover a relevant portion of the demand through the use of renewable sources (mainly solar). The obtained benefits were unquestionably relevant and allowed to realize more sustainable buildings, especially at the beginning of the application of this strategy.

However, as the progress went on, the limits of this approach started to show up in all their severity and the drawbacks worsened over the time. Specifically, three major issues can be highlighted:

- Overheating of the built environment, caused by the 'unbridled' and uncritical application of the 'energy conservation' principles. If on the one hand the previously discussed measures allowed to reduce the energy demand for space heating, on the other, they often increased the cooling loads to a significant extent. Such phenomenon is particularly relevant in case of non-residential buildings, where the improvement of the thermal insulation came along with the rise of the endogenous thermal loads. It is common knowledge that today many modern office buildings need to be cooled also during the winter season, even in cold climate locations.

- Change in the relative weight of the heating, cooling, lighting and electric energy demand. The application of an optimization process aimed at solely addressing the problems of space heating and domestic hot water production, for a period of some decades, led up to a significant reduction of the heating demand. At the same time, the expectations of occupants for higher levels of indoor environmental quality, either from the thermo-hygrometric point of view during the summer season or for the visual comfort, combined by an increasing use of electric appliances, caused the other entries of the energy balance of a building to extend their influence. The energy consumption related to cooling, artificial lighting and plug loads is today comparable with the heating energy demand. In particular, it is worth mentioning, that the optimization of natural

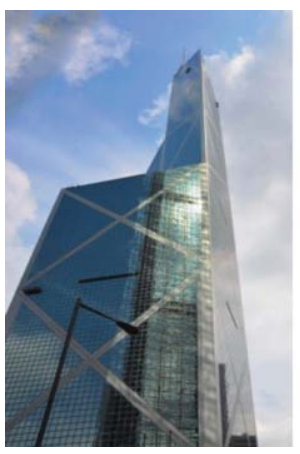

Hong Kong - Cina

$\mathrm{T}_{\text {design, winter }} \approx 9{ }^{\circ} \mathrm{C}$

$\mathrm{HDD} \approx 170^{*}{ }^{\circ} \mathrm{C} \cdot \mathrm{d}$

$\mathrm{T}_{\text {design, summer }} \approx 34{ }^{\circ} \mathrm{C}$

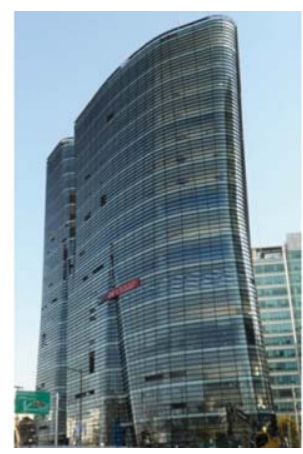

Seoul - South Korea $\mathrm{T}_{\text {design, winter }} \approx-11^{\circ} \mathrm{C}$ $\mathrm{HDD} \approx 2684^{*}{ }^{\circ} \mathrm{C} \cdot \mathrm{d}$ $\mathrm{T}_{\text {design, summer }} \approx 32{ }^{\circ} \mathrm{C}$

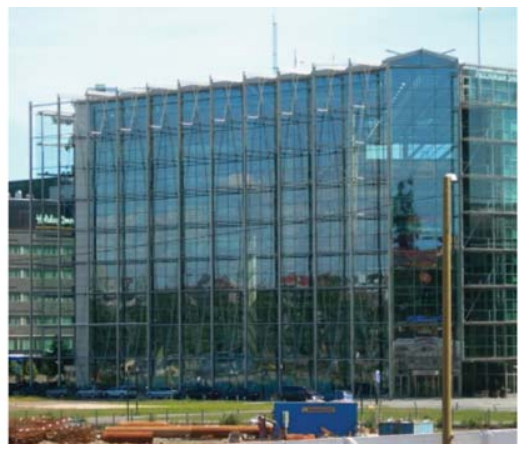

Helsinki - Finland

$\mathrm{T}_{\text {design, winter }} \approx-24{ }^{\circ} \mathrm{C}$ $\mathrm{HDD} \approx 4786^{*}{ }^{\circ} \mathrm{C} . \mathrm{d}$

$\mathrm{T}_{\text {design, summer }} \approx 25^{\circ} \mathrm{C}$

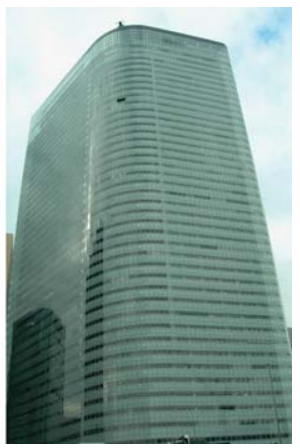

Tokyo - Japan $\mathrm{T}_{\text {design, winter }} \approx 1{ }^{\circ} \mathrm{C}$ $\mathrm{HDD} \approx 1569^{*}{ }^{\circ} \mathrm{C} \cdot \mathrm{d}$ $\mathrm{T}_{\text {design, summer }} \approx 33^{\circ} \mathrm{C}$

Fig. 2. Typical examples of building envelopes which were not designed in relation to exposition and climate: different expositions and climatic contexts, same design philosophy of the facade. 
lighting has often been a neglected element in the building design. Therefore, even considering the energy improvements of the light sources (of about an order of magnitude), the overall energy consumption for artificial lighting has increased in percentage.

- Consequences due to the so-called 'law of diminishing returns' (Shepard, 1974). This rule is common to many engineering and economic sectors, and states that in all processes, keeping to improve just one of the factors, while holding all others constant ('ceteris paribus'), will at some point yield lower incremental per-unit returns (Samuelson \& Nordhaus, 2001). In the case of the building envelope, this principle translates into the fact that the prolonged application of 'the energy conservation approach' has allowed to attain - so far - high performing solutions, but pushing this strategy any further will only provide marginal improvements, with ever growing costs. Torcellini, Pless, Judkoff \& Crawley (2007), for example, demonstrated that even optimizing the technological solutions so far explored to their best limits, the maximum achievable improvement, compared to the current energy performance of buildings, can be at most of about $50 \%$. A level that is far worse than the target imposed by the EPBD recast directive of 2010 (European Commission, 2010). A clear proof of such situation is represented by the trend of the loss coefficient for transmission, $\mathrm{H}_{T}$, and ventilation, $\mathrm{H}_{\mathrm{V}}$, over the time. These two quantities are defined by European and National standards (UNI EN 12831, 2006) and are the ratio between, respectively:

- the heat flux cumulatively lost by transmission through the facades and the outdoor-indoor air temperature difference,

- the enthalpy flux lost with the ventilation airflow rate and the outdoor-indoor air temperature difference.

Figure 3 shows the evolution of these two parameters for an exemplary, ideal, building. $H_{T}$ has been calculated considering an archetypal building of $100-\mathrm{m}^{2}$ floor area and assuming that all the transparent and opaque surfaces would have the U-value mandatorily set by the law at the corresponding

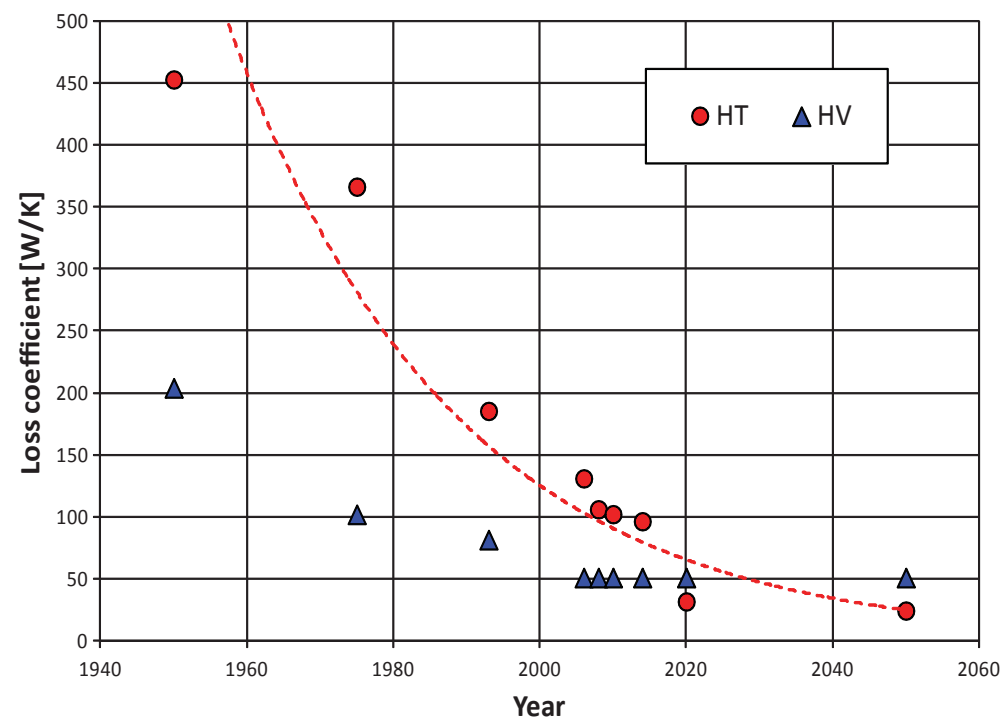

Fig. 3. Transmission and ventilation loss coefficients versus time for a typical residential building (100 $\mathrm{m}^{2}$ of floor area, window area $1 / 8$ of the floor area. $H_{T}=$ loss coefficient for transmission, $H_{V}=$ loss coefficient for ventilation). 
year (or the presumable value at the future time). The $\mathrm{H}_{\mathrm{V}}$ coefficient has been assessed assuming a reasonable air permeability for the building envelope at a certain time and the corresponding average air change rate by infiltration. A minimum limit value of $0.51 / \mathrm{h}$ for the air change rate $(\mathrm{ACH})$ was however kept, that is the one typically required by the technical standards in order to provide an adequate IAQ in residential buildings.

As it is possible to see from Figure 3, before the seventies, when thermal insulation was not mandatorily required, the energy losses for transmission was more than two times the energy losses for ventilation. By improving the performance of the building envelope, either in terms of thermal insulation and air tightness, it was possible to reduce these losses by a factor of about 3.5-4, in a period of fifty years. Nevertheless, in 2006 the ratio between $\mathrm{H}_{T}$ and $\mathrm{H}_{V}$ was still of about 2. However, the further enhancement of the thermal insulation, enforced by the current and future regulations, is - and will - strongly change this picture. In 2020 the ventilation losses will, likely, exceed the transmission losses, since it will be not possible to reduce the ventilation airflow rate anymore (as mentioned, a minimum $\mathrm{ACH}$ is always required to assure a satisfactory indoor air quality). This implies that, from now on, it will be unwise to give too much attention to the optimization of the thermal resistance of the facade. It will be far more effective to find a way for saving energy for the fresh air pre-heating.

Moreover, all these issues are being combined with a deep and rapid strengthening of the requirements regarding the energy efficiency in buildings. The new European legislative framework (European Commission, 2010) in fact, sets the ambitious objective that all the new buildings will have to satisfy, within 2020 (2018 for public buildings), the 'nearly Zero Energy Building' (nZEB) target.

This picture reaffirms the key role played by the facade in the energy design of a building and demands for a revolution of the traditional constructive habits. A radical change in the dogma on which facade engineers and architects have based their professional certainties for decades is, nevertheless, required.

In this paper this change of concepts will be analysed from a theoretical point of view, highlighting those key elements that need to be considered for the future technological development of facades. Moreover, after this general overview, some practical examples of innovative solutions for responsive and dynamic building envelope components will be presented and discussed. They refer to a research activity that is running since the beginning of the year 2000 at the Department of Energy, Politecnico di Torino. The main operative features of the components and their measured performance will be presented and critically analysed in the perspective of their dynamic behaviour.

\section{From a static envelope to dynamic and multifunctional facade modules - A paradigm shift}

'Paradigm shift' is today a trendy term, all too often abused in the community of architects and designers. Besides its Greek original meaning, a 'paradigm' in the Philosophy of Science identifies a disciplinary matrix for a given scientific community. In this matrix a globally shared vision is crystallized. Probably Khunz gave the best definition (1970): "It is a scientific result that is universally recognized and that, for a period of time, provides a model and solutions for a given scientific community." Therefore, a 'paradigm shift' (or revolutionary science) is a radical change in the basic assumptions that has ruled a certain research and/or technological environment for a long time. This definition perfectly fits in the current framework of the building envelope. As highlighted in the previous section, limitations and emerging requirements are demanding for it. 
The principles of the 'energy conservation' approach, which saw the apex of its maturation in the idea of the 'passive house', appear today to be out-dated. To be able to fulfil the requirements set forth by the nZEB and/or ZEB buildings, a wider view must be adopted. First of all, heating, cooling lighting and plug loads must be simultaneously addressed and the following 'changes of mind' must be achieved:

- From 'Shield, Barrier, Separation' to 'Interface, Host location, Management'.

Today it is mandatory to exploit the opportunities offered by the local climate and by the natural resources, instead of working against them, as suggested in the past by the energy conservation beliefs. We must switch from an attitude of denial to a positive approach. The envelope should be no more perceived as a 'problem', a 'difficulty', but it should be considered as an 'opportunity', a 'potentiality' and, of course, a 'challenge'. The building envelope, more than a 'construction component', will have to be seen as a 'place', a spatial location. It represents the surface that divides the conditioned and controlled environment from the external environment, and through it all the mass and energy transfers take place. Hence, the building envelope offers a huge interface that can be effectively used to manage the mass and the energy balances of the built environment and to host technologies for the exploitation of renewable (non-carbon) sources and/or low quality energies (low exergy).

- From 'Invariable, Static, Generic' to 'Dynamic, Adaptive, Responsive, Customized'.

The idea that the constructive elements of a building are components that do not change their structure and aspect, and whose features, properties, functions and behaviour are immutable, starts to be strongly limitative and unsatisfactory. Moreover, the frequently adopted 'one-sizefits-all' approach, i.e. a generic facade configuration is suited for all the conditions (see e.g. Figure 2), is not functional at all. The innovation of the building envelope that appears far more promising consists in passing from the concept of insulation to that of adaptability. The best facade is not necessarily the one that shows the higher air tightness, thermal insulation and the one that maximizes the solar heat gains. Depending on the season, working conditions and user preferences the building envelope could be asked to allow a higher/lower heat flux to take place, to store/release the energy, or to tune the ventilation airflow rate or, finally, to adjust its transparency.

- From 'Single function, Single behaviour' to 'Multifunctional and Integration'.

The vast majority of building envelope technologies currently available on the market is made of 'passive', e.g. 'resistive' ${ }^{2}$, elements. Even when some active technologies (for example PV systems) are present, they are more incorporated as an 'addition' to the facade than being functionally/structurally integrated. A significant improvement of the energy efficiency can only be achieved by conceiving 'active' components, where the equivalent electric network becomes a combination of resistors, capacitances and current generators. Such multifunctional modules, typically host generation/conversion systems (as for example the technologies for the on-site exploitation of the solar radiation), play a role in the ventilation (being used as air heat exchangers, air pre-heaters, ventilation outlets/inlets, ducts etc.) and are combined with the lighting strategies. In order to be efficiently exploited, these dynamic components must not be integrated just adopting a mere 'additive principle' (e.g. 'sticking' the new component on a traditional

\footnotetext{
${ }^{2}$ That is, adopting the well-known electric analogy for the heat transfer, the traditional building envelope components can be represented by means of a network of resistors and capacitors.
} 
facade), but they must become an intimate part of the HVAC and artificial lighting systems and be controlled in a holistic and coordinated way with them.

Therefore, according to this paradigm shift, opaque and transparent components become a 'living' membrane used to "filter, store and/or modify the mass and heat fluxes, hence managing the external environmental parameters to satisfy the internal needs and to guarantee an optimal IAQ" (Goia, Perino, Serra \& Zanghirella, 2010). The keywords on which their development will have to be based are (Van der Aa, Heiselberg \& Perino, 2011): responsivity, adaptability, dynamic behaviour, integration/interactivity, harmonization (tuning) with the indoor/outdoor environment, multi-functionality, as schematically shown in Figure 4.

\section{The different scale of the research}

Translating this revolution of concepts from a vision to the practice is not trivial and a systemic approach is needed.

Some researchers (Goia, 2013) suggested to subdivide and structure the research on three different levels, corresponding - to a certain extent - with the dimensional scales of the building envelope:

- the concept level,

- the system level,

- the material level.

Clearly, the process is such that each level can 'cross-fertilize' the others, transforming in this way an apparently linear flow path into a research development that is iterative.

\subsection{The concept level}

The aim of this level is to explore new ideas and visions, analysing them from a theoretical point of view in order to obtain information on the 'working principles'. The objective is to identify which

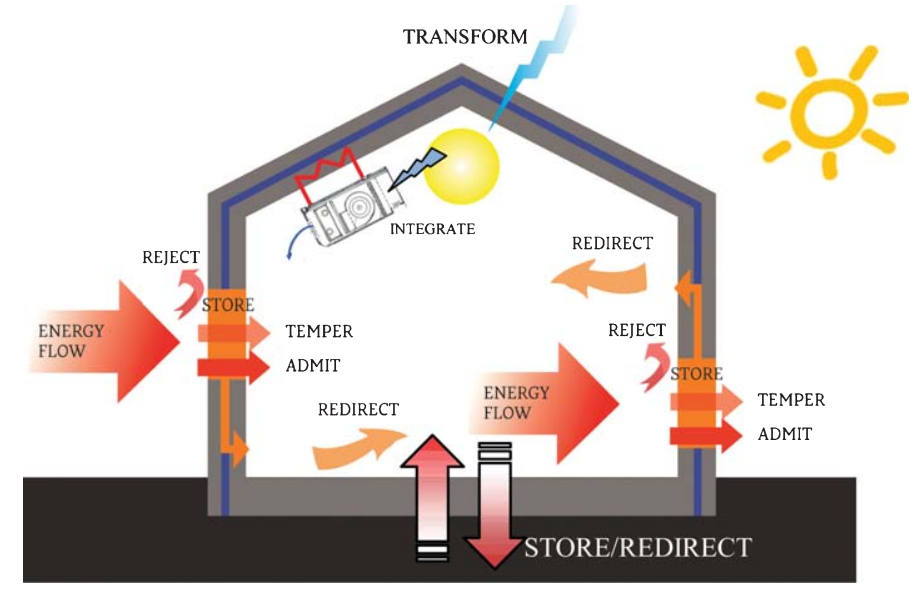

Fig. 4. Conceptual scheme of dynamic, responsive, multifunctional and integrated facades (adapted from Van der Aa et al., 2011). 
lines to follow to conceive and develop new components and to optimize the strategies of integration with the systems and the building. From a practical point of view, this level tries to give an answer to the question of 'what' would be desirable to obtain from a new product, without worrying about 'how' to do it (hence no attention is put on the technological feasibility of the solutions or on the actual availability of materials with the desired properties).

It is a very theoretical phase and, apparently, far from the applicative reality. Nevertheless, it represents the fundamental step to establish, for example, what is the 'range' of properties that a dynamic envelope should have to satisfy the adaptability requirements and what is the 'amplitude' of their variability (see e.g. Favoino, Overend \& Jin, 2015). It is also useful to define control strategies, the degree of integration with other building/systems components, the multi-functionality level and the benefits in terms of energy savings. Since the development of this kind of analyses needs a 'total energy' approach (at least heating, cooling and lighting must be simultaneously considered) the simulation instruments currently available are often inadequate and the researchers need to develop numerical models ad hoc. Such a difficulty explains why a limited number of studies and papers can be found in the literature.

A first and interesting attempt in this field was done by Goia (2013), who developed a sensitivity analysis to evaluate the influence of various thermal properties of the building envelope on the total energy demand (to identify which are the most influential ones) and the range of variability which is needed to proceed to the energy optimization of the building. An example of product development based on the 'concept level' approach is available in Loonen, Singaravel, Trčkal, Cóstola \& Hensen (2014).

More recently, Kasinalis, Loonen, Costola \& Hensen (2014) presented a design and analysis approach for the so called CABS (Climate Adaptive Building Shell), exploring the possibility of conceptually ideate and optimize an adaptive facade (on seasonal basis) which allows for the minimization of the energy consumption. The obtained results show how a responsive building envelope component, which can dynamically modify six of its properties (density, specific heat and thermal conductivity of the material, external absorption coefficient of the surface, opaque on transparent surface ratio, typology of glazing), allows an improvement of $16-18 \%$ of the performance in comparison with the state-of-the art facades based on the traditional static concept (Favoino, Jin \& Overend, 2014b).

\subsection{The system level}

This level is focused on the identification of technological solutions to build modular and multifunctional facade modules. The objective is to obtain building envelopes which are almost self-sufficient from the energy point of view, creating systems which integrate many functionalities (for example: ventilation, thermal exchange and heat recovery, lighting, thermal storage, energy conversion systems, HVAC components, solar shading devices etc.). Even though the conception of a self-sufficient skin appears to be a very ambitious goal, and its translation into a product ready for the market even more difficult, this idea is considered very promising. Proof is that some leader companies in the sector are developing, or have already proposed, multifunctional facade modules inspired on this philosophy (for example the $E^{2}$ facade from Schüco and TEmotion from Wicona). Quite numerous are also the examples of studies on these kind of envelopes which are available in the literature (Quesada, Rousse, Dutil, Badache \& Hallé, 2012a and 2012b; Saadatian, Sopian, Lim, Asim \& Sulaiman, 2012). 
Even though the configurations can be extremely various, it is however possible to identify some basic features which are common to the multifunctional building facades:

- the management of the heat fluxes. This is obtained - in general - minimizing the transmission losses through the component (maximizing its thermal resistance) and controlling the heat transfer by means of the ventilation, or the charge/discharge of thermal storages (in facade) or, eventually, with the use of heat transfer fluids and devices (e.g. Peltier cells);

- the on-site conversion of solar radiation, done with active systems (for example PV, PVT, etc.) or with passive techniques (managements of free gains);

- the reduction of the energy inefficiencies at the building scale (for example avoiding long ducts for ventilation, which cause pressure drops);

- the integration with mechanical systems, using the facade as: a terminal device, a heat recovery system, a ventilation outlet/inlet, or as a source/sink of thermal energy;

- the optimization of daylighting;

- the energy storage capability (using the envelope as a LHTES. Latent Heat Thermal Energy Storage System).

Examples of MFM are shown and analysed in Xu and Van Dessel (2008) and in Favoino, Goia, Perino \& Serra (2014a). A practical example of these multifunctional facade modules will also be presented and discussed in Section 4.1.

\subsection{The material level}

This is the phase where most of the detailed studies have been developed. The objective is to identify those materials and/or sub-components whose features are suitable to build multifunctional facade modules and to characterize their behaviour. It is hence a functional and preliminary step for the design at the system level. The aim is to answer the question 'how' to practically implement the outcomes obtained in the concept level.

The incredible development of the material science that took place in the last decade, and the consequent availability of new products, offer great opportunities for the realization of innovative envelope components.

Among others, the following materials show the most promising application:

- super-insulating materials (especially VIPs - Vacuum Insulation Panels - and aerogels),

- gas-filled panels,

- Phase Change Materials (PCMs, slurry PCMs),

- non-conventional glazings (thermotropic, photochromic and electrochromic glazings),

- coating and membranes with selective/reflective optical properties,

- coatings with specific physical/chemical behaviour (hydrophobic finish, photocatalytic coatings etc.).

In Section 4.2 some researches performed on transparent components will be presented; they are focused on the integration of phase change materials into conventional double/triple glass units. 


\section{Practical examples}

In the following sections an overview of some of the most significant research projects carried out by the TEBE Research Group at the Department of Energy - Politecnico di Torino will be given. This field of research started in the year 2000 and, along the time, has been focused on various innovative building envelope components, either transparent or opaque. Specifically, the activities were mainly performed at material and system level and concentrated on multifunctional transparent facades (climate facades, hybrid-ventilated facades, naturally ventilated facades. Corgnati, Perino \& Serra, 2007; Serra, Zanghirella \& Perino, 2010; Goia, Perino, Serra \& Zanghirella, 2010), smart glazing systems (with a special attention on PCM based configurations. Goia et al., 2013; Goia et al., 2014; Goia, Zinzi, Carnielo \& Serra, 2015) and Multifunctional Facade Modules (MFMs) (Favoino, Goia, Perino \& Serra, 2012; Favoino et al., 2014a).

\subsection{ACTRESS, an example of a multifunctional facade module}

The ACTRESS (ACTive, RESponsive and Solar) prototype was designed as a prefabricated unit of one storey high (3,50 m). It consists of an Opaque Sub-Module (OSM) and a Transparent Sub-Module (TSM) (Fig. 5). The window to wall ratio (WWR) was determined on the basis of a preliminary numerical simulation. A WWR of about 50\% demonstrated to be one with the lowest total (cooling, heating and lighting) yearly energy demand for the local climate of Torino, regardless the orientation of the facade (Favoino et al., 2012; Goia, Haase \& Perino, 2013).

The ACTRESS module is characterized by a moderate 'hardware' integration with a potential HVAC system, but by a strong functional coupling with the mechanical installations. The opaque module is a ventilated facade with the external skin made of three PV panels (amorphous aSi, nominal

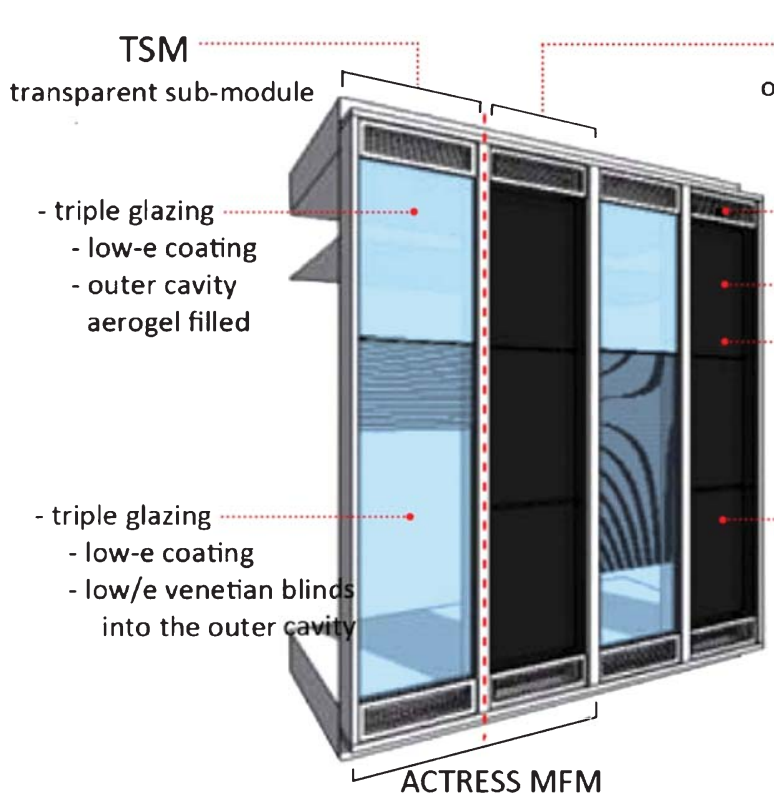

OSM

opaque sub-module

OVF Opaque Ventilated Facade ventilation grid aSI PV panels $(3 \times 29 \mathrm{Wp})$

Ventilated cavity behind the aSI PV layer: - cavity thickness $=120 \mathrm{~mm}$ - equipped with 4 axial fans Sandwich wall panel behind the ventilated cavity: - gypsum wall board - $25 \mathrm{~mm}$ VIP layer - gypsum wall board - PCM layer (Tmelt $\left.=27^{\circ} \mathrm{C}\right)$ - electric heatd carpet - PCM layer (Tmelt $=23^{\circ} \mathrm{C}$ )

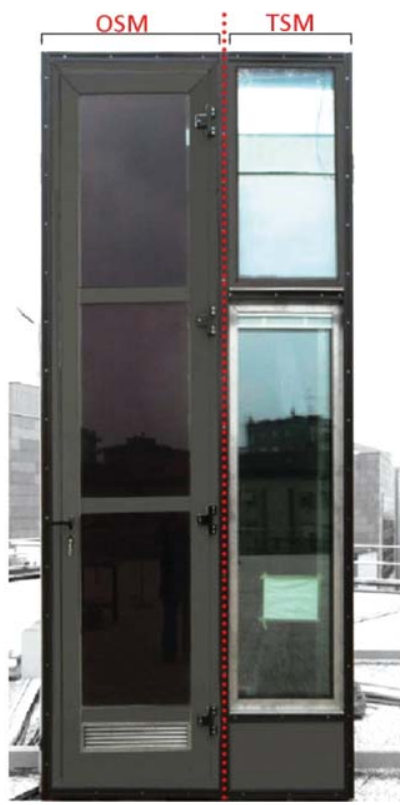

Fig. 5. The ACTRESS prototype (left) and a sketch of the various components (right). 
power $87 \mathrm{~W}$ ). The ventilated cavity can be operated to provide various ventilation strategies (supply air, outdoor air curtain and exhaust air) and modes (natural, hybrid and mechanical ventilation; a thermal buffer mode, with inlet and outlet grids closed, may also be realized to improve the thermal insulation). The inner skin is made of a gypsum-board panel that provides mechanical resistance to the wall structure, a Vacuum Insulation Panel (VIP, thickness $25 \mathrm{~mm}, \lambda 0.005 \mathrm{~W} / \mathrm{mK}$ ) and two layers of Phase Change Materials (PCMs, melting temperatures of $27^{\circ} \mathrm{C}$ and $23^{\circ} \mathrm{C}$ ). Finally, three electric heated carpets (heat output: $50 \mathrm{~W}$ each), directly powered by the PV panels, are located in between the PCM layers, thus allowing for an active thermal energy storage (LHTES, e.g. activation of the PCM on-demand). The PV panels are integrated in the facade with the specific aim of improving the energy self-sufficiency of the module, rather than 'generically' produce electric energy to be sold to the network. According to this concept, the power converted by the PV panels can be directly used in the ACTRESS module to power the fans (when the air cavity is mechanically ventilated) and the shading device, or to store thermal energy in the PCM layers. If the electric energy production exceeds the module self-demand, the extra production can be sold to the network.

The transparent sub-module presents a lower degree of complexity. It is made of two glazing systems: the lower glazing (about $2 / 3$ of the total transparent surface) is a triple low-e coated glazed unit (6/15/6/15/6) with Argon and with the outer cavity hosting a high reflective, low-e coated venetian blind, for solar and light transmission control; the upper part of the transparent sub-module is made of a triple-glazing, whose outer cavity is filled with granular, translucent, aerogel ( $\lambda$ aerogel $0.009-0.012 \mathrm{~W} / \mathrm{mK}$ ), while the inner cavity is filled with Argon.

The key aspect of the ACTRESS modules lies in its dynamic and active properties, which can be continuously modified to achieve better energy and comfort performance. The highest degree of dynamicity is reached in the opaque module where several combinations of ventilation strategies and thermal energy storage activations may result in very different behaviours. The transparent module instead shows a more limited degree of responsiveness. This surface, in fact, is made of highly performing technologies, but only the solar shading system allows for a dynamic behaviour (which, nevertheless, affects to a great extent the overall performance of the facade).

During the summer season, the opaque module typically adopts an outdoor air curtain strategy and operates in mechanical mode (for days with low solar radiation natural ventilation can be used instead). The PV panels provide the power to activate the fans and to control/displace the shading device. The forced ventilation of the air cavity allows to reduce the solar heat gains and, at the same time, lowers the temperature of the PV panels increasing their efficiency. The super insulation layer (VIP) helps in thermally disconnecting the indoor environment from the air cavity, while the PCM layers increase the thermal inertia of the room. Specifically, the PCM is exploited as a passive thermal storage, smoothing and delaying the thermal wave through the facade and reducing/shifting the cooling loads caused by internal and solar gains. The operation of the transparent module is more straightforward. Since in this period the concern is to prevent the overheating of the indoor environment, the shading device is operated in order to avoid the direct solar radiation to enter into the room. The upper glazing, thanks to its light diffusing behaviour, the elevated position and the good thermal insulation properties aim at providing the best opportunities for daylighting, keeping the solar heat gains as low as possible.

During the winter season, the opaque module operates either with the supply air strategy or the thermal buffer, depending on the outdoor air temperature and solar radiation levels. If the incident solar radiation is high enough, the air cavity can be used to pre-heat the ventilation air and the facade is configured in the supply air strategy (natural and mechanical ventilation modes can be used, depending on the incident solar radiation). During the night, or during cloudy days, the thermal 
buffer configuration is adopted, since it allows a better thermal insulation and helps in reducing the heat losses through the envelope. The electric energy converted by the PV panels is mainly used to feed the heated carpets and to produce thermal energy that is stored in the two PCM layers. This allows to accumulate the thermal energy during the day, when the heating demand is low, and to use it afterwards, when the heating demand increases (better match between energy demand and production).

Finally, as far as the transparent module is concerned, the shading device can be operated, both to control solar gains and to prevent glare discomfort, by means of the electric motor powered by the PV layer.

A full-scale prototype of the ACTRESS module was built, installed on the TWINS facility (Corgnati et al., 2007) and tested for the local climate of Torino (45.08 N, 7.68E, 2894 HDD) during a period of almost two years. The measurement apparatus consisted of a total of 68 sensors ( 52 thermocouples, 9 heat-flux meters, 4 pyranometers, sensors to measure fans angular speeds, PV voltage and current), connected to a data logger. A comprehensive and critical analysis of the data can be found in Favoino et al. (2014a). In the following, for the sake of brevity, some resumed results will be discussed.

As expected, the overall thermal insulation of both the opaque and transparent modules is excellent (Table 1). The additional use of a low-e coated solar shading device allows to improve the thermal insulation of the glazing of about $2 \%$.

The aerogel glazing, though it has a very good thermal insulation, presented severe drawbacks due to the very high surface temperatures it reached. Peak values as high as $45^{\circ} \mathrm{C}$ were measured, which can seriously compromise the thermal comfort conditions in the room. The aerogel glazing overheating (due to the absorbed solar radiation), also showed a disturbing 'thermal tail' that lasts about four hours and affects the performance of the component also during the late afternoon/night.

In relation to the dynamic features of the facade, the adoption of the supply air strategy (with natural ventilation) during the winter demonstrated to be an effective measure to preheat the ventilation air. The measured pre-heating efficiency (Corgnati et al., 2007), assessed for the daytime, highlighted the following achievements:

- for about $10 \%$ of the daytime the air can be effectively preheated in the air cavity and directly supplied to the indoor environment at the indoor design temperature of $20^{\circ} \mathrm{C}$, thus zeroing the ventilation losses;

- for $5 \%$ of the working time, the air can be heated at a temperature above $20^{\circ} \mathrm{C}$ (that is, the facade becomes an active element being able to help heating the room);

- for more than $80 \%$ of the working time it is possible to have a certain degree of pre-heating of the ventilation air in the cavity (that is: the pre-heating efficiency is positive).

During the summer, to limit the heat gains, the outdoor air curtain strategy is used instead. For these operative conditions the dynamic insulation efficiency is of interest (Corgnati et al., 2007). Its value revealed to be around 1 for about $90 \%$ of the working time (meaning that the opaque module

Table 1

Measured $U$ values for the OSM and TSM

\begin{tabular}{lcccc}
\hline Component $\longrightarrow$ & OSM & $\begin{array}{c}\text { TSM - aerogel } \\
\text { glazing }\end{array}$ & $\begin{array}{c}\text { TSM - lower glazing } \\
\text { (raised venetian blind) }\end{array}$ & $\begin{array}{c}\text { TSM - lower glazing } \\
\text { (lowered venetian blind) }\end{array}$ \\
\hline $\mathrm{U}-$ value $\left[\mathrm{W} /\left(\mathrm{m}^{2} \mathrm{~K}\right)\right]$ & 0.08 & 0.58 & 0.63 & 0.62 \\
\hline
\end{tabular}




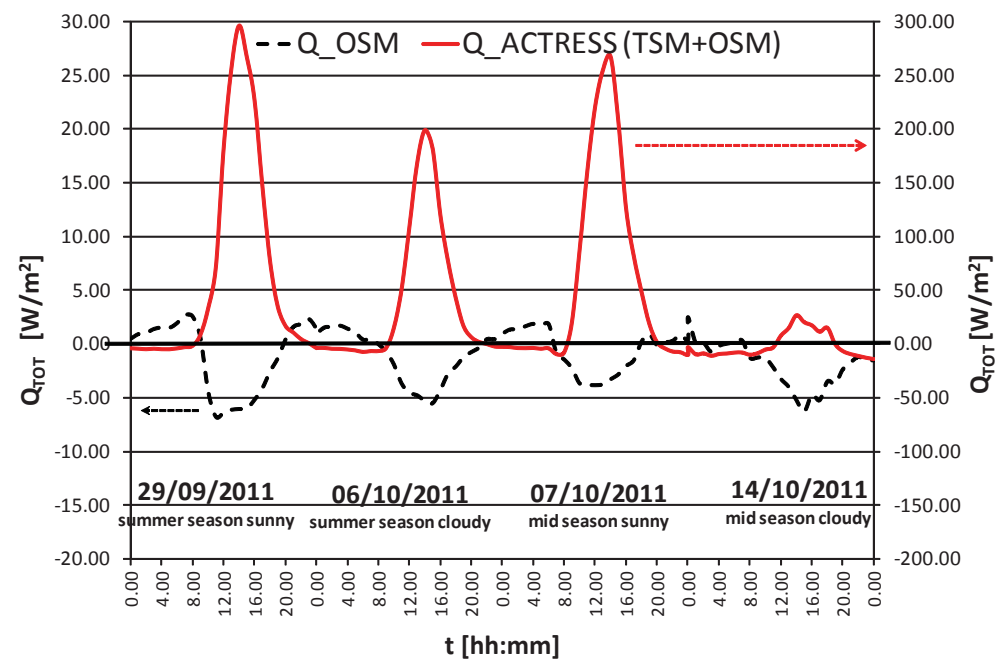

Fig. 6. Total heat flux exchanged through the opaque sub module (OSM) and the ACTRESS modules - time profiles.

behaves almost like an adiabatic surface). This excellent result is due to the coupling of a static feature, that is, the very low thermal conductance of the inner skin, and a dynamic behaviour, that is, the cavity ventilation and the presence of a latent heat thermal energy storage (LHTES) that can store thermal energy during the peak period of the heat gains and release it afterwards (e.g. passive activation of the PCM).

In particular, the LHTES presents an interesting behaviour and is significantly improving the building element responsiveness. This is clearly shown for example in Figure 6, where the time profiles of the specific heat fluxes through the opaque module alone (black dotted line) and through the whole ACTRESS module (red line) are plotted versus time, for typical days of the summer season. As expected, the transparent module is responsible of the major part of the energy entering into the room through the facade, but its profiles present peak values that are simultaneous to the peak value of the specific heat fluxes absorbed by the PCM layers.

As it is possible to see, in peak conditions, the LHTES is able to remove from the room a certain amount of the specific heat fluxes entering through the facade. Unfortunately, the size of these two heat fluxes is quite different (Fig. 6) and an improvement in both the amount of the thermal energy that can be buffered in the opaque module and in the heat exchange mechanisms is still needed.

Also during the winter the activation of the LHTES by means of the PV panels provides significant improvement in the energy efficiency of the system, even if the monitoring campaign highlighted a non-optimal exploitation of the stored energy. The overall average efficiency of the PV+LHTES system, in fact, was about $25 \%$.

Finally, the overall energy performance of the ACTRESS prototype was synthetically evaluated by means of the specific daily energy, $E_{24}$, exchanged through the facade along the 24 hours. Specifically, three quantities have been used, that is: the amount of energy that enters, $E_{24}^{+}$, or leaves, $E_{24}^{-}$, the indoor environment through $1 \mathrm{~m}^{2}$ of the facade module, and the net value $E_{24}^{+}=E_{24}^{+}\left|E_{24}^{-}\right|$, being:

$$
E_{24}^{+}=\frac{\int_{6 \mathrm{am}+1}^{6 \mathrm{am}} \dot{\mathrm{Q}}_{\mathrm{tot}}^{+} \cdot \mathrm{d} \tau}{A_{\mathrm{MFM}}}\left[\mathrm{Wh} / \mathrm{m}^{2}\right]
$$$$
E_{24}^{-}=\frac{\int_{6 \mathrm{am}+1}^{6 \mathrm{am}} \dot{\mathrm{Q}}_{\mathrm{tot}}^{+} \cdot \mathrm{d} \tau}{A_{\mathrm{MFM}}}\left[\mathrm{Wh} / \mathrm{m}^{2}\right]
$$ 
Table 2

Measured values of the overall thermal energies exchanged between the outdoor and the indoor environment through the ACTRESS module

\begin{tabular}{|c|c|c|c|c|c|c|}
\hline $\begin{array}{l}\text { Average } \\
\text { Day }\end{array}$ & $\begin{array}{c}\text { Average } \\
\mathrm{T}_{\text {outdoor }}\left[{ }^{\circ} \mathrm{C}\right]\end{array}$ & $\begin{array}{c}\text { Daily Irradiance } \\
{\left[\mathrm{Wh} / \mathrm{m}^{2}\right]}\end{array}$ & $\begin{array}{c}E_{24}^{-} \\
{\left[\mathrm{Wh} / \mathrm{m}^{2}\right]}\end{array}$ & $\begin{array}{c}E_{24}^{+} \\
{\left[\mathrm{Wh} / \mathrm{m}^{2}\right]}\end{array}$ & $\begin{array}{c}E_{24} \\
{\left[\mathrm{Wh} / \mathrm{m}^{2}\right]}\end{array}$ & Operating conditions \\
\hline Winter & -0.3 & 4649.1 & -76.84 & 236.37 & 159.53 & $\begin{array}{l}\text { Supply air \& natural ventilation. LHTES } \\
\text { activated with the PV. Lowered } \\
\text { venetian blinds. }\end{array}$ \\
\hline Summer & 22.2 & 2537.9 & -24.84 & 212.86 & 188.02 & $\begin{array}{l}\text { Outdoor air curtain \& mechanical } \\
\text { ventilation. LHTES passively exploited. } \\
\text { Lowered venetian blinds }\end{array}$ \\
\hline Mid-season & 16.5 & 2563.9 & -48.35 & 254.63 & 206.28 & $\begin{array}{l}\text { Outdoor air curtain \& mechanical } \\
\text { ventilation. LHTES passively exploited. } \\
\text { No venetian blinds }\end{array}$ \\
\hline
\end{tabular}

where $\dot{\mathrm{Q}}_{\mathrm{tot}}^{+}$and $\dot{\mathrm{Q}}_{\mathrm{tot}}^{-}$are the entering/exiting total specific heat fluxes measured during the monitoring (they account, cumulatively, for convective, short and low wave heat exchanges).

As an example, Table 2 resumes the measured $E_{24}$ values for an average winter, summer and mid-season day, respectively.

As one can see, the heat losses during the winter are very low. The presence of the LHTES, actively charged during the daytime by means of the PV system, can compensate, to a large extent, the heat fluxes exiting during the night. On the overall ${ }^{4}$, the facade ensures a net positive energy even in the cold season (e.g. $E_{24}>0$ ).

It is worth noting how the energy exchanges through the module can be effectively managed by adopting a proper choice of the operational modes and of the adaptable features of the component; as a result the $E_{24}^{+}$is of the same order of magnitude during the whole year. Furthermore, during the summer, by means of the passive activation of the PCM layers, it is also possible to have a negative energy exchange (e.g. reject part of the heat gains towards the outdoor environment: $E_{24}^{-}=$ $-24.84 \mathrm{Wh} / \mathrm{m}^{2}$ ), which helps in reducing the energy demand for cooling.

Roughly considering the heat fluxes to be positive for twelve hours (during the day) and negative for the remaining time (during the night), the thermal energies shown in Table 2 would correspond to average specific heat fluxes ${ }^{5}$ between:

- $6.4 \mathrm{~W} / \mathrm{m}^{2}$ and $+19.6 \mathrm{~W} / \mathrm{m}^{2}$ in winter

- $2.1 \mathrm{~W} / \mathrm{m}^{2}$ and $+17.7 \mathrm{~W} / \mathrm{m}^{2}$ in summer

- $4.0 \mathrm{~W} / \mathrm{m}^{2}$ and $+21.2 \mathrm{~W} / \mathrm{m}^{2}$ in mid-season.

\footnotetext{
${ }^{3}$ The superscript ' + ' means that only positive heat fluxes are taken into account in the integration (and viceversa for the superscript '-').

${ }^{4}$ Care must be taken when net energies are analysed. The integration over a day does not allow to account for possible mismatch problems (that is positive heat fluxes during the day that cannot be exploited to compensate the heat losses during the night). In this case, thanks to the LHTES system, the likelihood of mismatch between energy demand and production is reduced. Still problems of non-complete exploitation of the diurnal energies may arise.

${ }^{5}$ These are mean values over the day and over the whole facade module. It has to be remembered that during the three different seasons the facade is operating adopting different working strategies.
} 


\subsection{SMARTGlass, a responsive glazing integrating PCMs}

A new concept of transparent facade was developed, integrating Phase Change Materials PCMs in the air gap of multiple glazing in order to better exploit solar heat gains and to increase the thermal inertia of the glazed system. Two configurations were tested (Fig. 7): the first adopting a paraffin wax with melting temperature $35^{\circ} \mathrm{C}$ inserted in a double glazing, mainly aimed at reducing the cooling loads in the summer period; the second coupling the same PCMs, inserted in a triple glazing, with a thermotropic glazing (TT+PCM), so to increase the responsiveness of the system to solar radiation, thus achieving a better control on the 'charge' phase of the PCM layer and contemporarily improving the winter behaviour thanks to a higher thermal resistance.

A detailed literature review of the developed and tested PCM glazing systems can be found in Goia et al. (2013), Bianco (2014), Goia, Bianco, Cascone, Perino \& Serra (2014), Goia et al. (2014) and Goia et al. (2015).

The main expected benefits of a glazing integrating PCMs are:

- during the summer period, a reduction and shift of the solar heat gain through the glazing, which means a decrease in cooling loads and in cooling energy demand;

- during the winter period, a reduction in the 'mismatch' between the heating energy demand and the solar energy availability thanks to the buffering effect;

- an improvement of thermal comfort, due to a better control of the internal glass surface temperatures;

- a better control of the visible solar radiation and a reduction in the glare risk.

As far as the first configuration is concerned, research has proved that the PCM glazing concept can be effective only when some conditions are realized. Some drawbacks can appear and need to be properly managed. In particular the control on the 'charge' phase of the PCM layer is necessary to prevent overheating phenomena due to the complete melting of the PCMs, as well as the control on the 'discharge' phase is also necessary to avoid either unwanted heat loss (in the winter period) or heat gain (in the summer period).

The 'charge'/'discharge' phase control of the PCM layer is the main relevant aspect to be faced. The first configuration, even showing a high potential in reducing direct solar irradiance entering the room

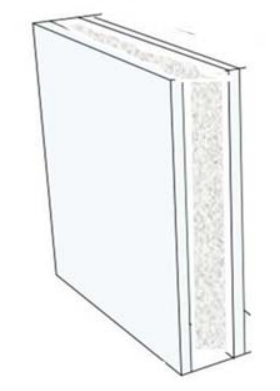

PCM in Double Glazing

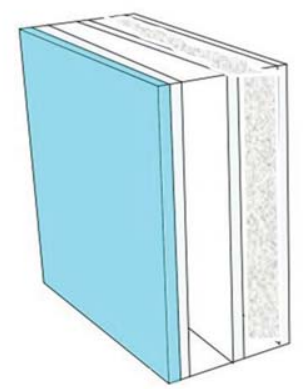

PCM in Triple Glazing (PCM_IN) + Thermotropic

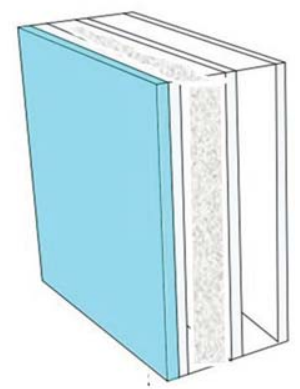

PCM in Triple Glazing (PCM_OUT) + Thermotropic

Fig. 7. Glazing filled with PCMs: double-glazing configuration and triple-glazing configurations (PCM_IN and PCM_OUT) coupled with a Thermotropic. 
(reduction of $1 / 5$ of the entering energies if compared to a conventional clear+clear double glazing), didn't allow for an optimized control of solar radiation, since in days characterized by high solar irradiance the melting process at 4 p.m. was completed and very high internal surface temperatures were reached thus causing noticeable thermal discomfort. Moreover the PCMs glazing shows a low performance in the winter period, if compared to a conventional argon filled and low-e coated double unit glazing, due to the higher conductivity of PCMs and the impossibility to reduce the IR exchange through the adoption of a low-e coating.

Starting from this experience a new concept has been conceived and tested: a thermo-tropic (TT) layer was included in the PCM window, so that the complete melting of the PCM layer could be avoided, and a triple-glazed configuration was adopted in order to increase the thermal resistance of the system (PCM+TT).

This new prototype was expected to provide a better control on solar energy transmitted and to present an increased thermal inertia, thus acting simultaneously as solar shading device, storage medium and glazing surface temperature moderator.

The adoption of the TT layer allows for a dynamic control of the solar transmission, switching from an 'off' to an 'on' state in the temperature range of $20-40^{\circ} \mathrm{C}$ with a corresponding solar transmittance ranging from 0.69 to 0.41 .

The triple glazing (TGU) had one cavity filled with PCM and the other one filled with Argon; moreover the two glass surfaces facing the Argon-filled cavity were low-e coated. The thermo-tropic glazing was placed outside, in front of the TGU, and two configurations were tested, placing the PCMfilled cavity towards the outdoor (TT+PCM_OUT) and towards the indoor environment (TT+PCM_IN) respectively.

The coupling between PCMs and TT layer was chosen for the very good match between the switching range of the TT layer and the phase change range of the PCMs: actually when the PCM starts its phase change, its absorptance decreases and the transmittance increases and, contemporarily, the TT layer starts to reduce its transmittance, thus lowering the solar radiation reaching the PCM layer.

The PCM+TT prototypes were tested by means of the outdoor test cell facility TWINS and compared with a reference TGU (Fig. 8). The two samples were installed on the same facade (south exposed) and continuously monitored through a measurement apparatus consisting of thermocouples, heat flux meters and pyranometers. A detailed description of sensors and of the measurement methodology are reported in Goia et al. (2014). For the sake of brevity, just the more relevant results are reported here.

The role of the increased thermal inertia in the TT+PCM is shown in Figure 9, where the time profile of the surface heat flux is plotted for different 'typical days', comparing the two configurations (TT+PCM_IN and TT+PCM_OUT) with the reference technology (TGU).

It is evident that both the configurations show the ability in smoothing and shifting (to a certain extent) the peak of the heat flux exchanged by convection and long-wave radiation. The highest reduction can be observed in days characterized by high solar irradiance, when the entering heat flux is reduced to about one third if compared with the reference TGU.

During the evening, the 'discharge phase' of the PCM layer occurs and the energy accumulated within the PCM layer is released in the indoor environment from approximately 6 p.m. onwards. At that time, the heat flux exchanged in case of the reference technology drops very quickly as soon as the facade is no longer exposed to direct solar irradiation. This phenomenon is particularly relevant when the day is sunny, while it is almost negligible during cloudy days. 
a)

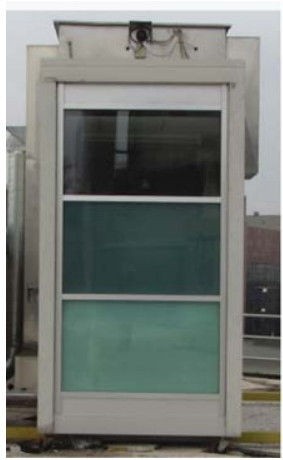

b)

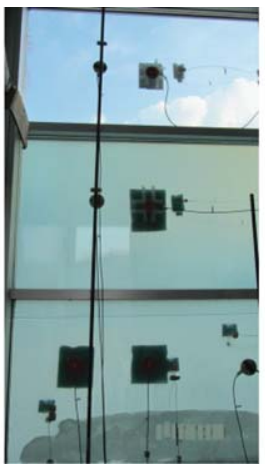

c)

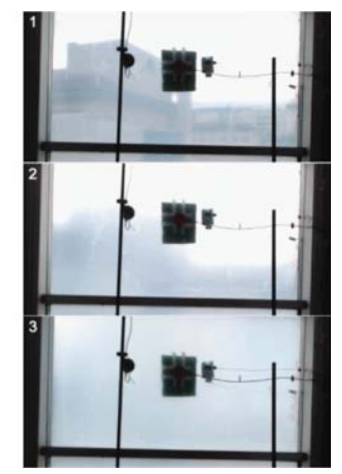

Fig. 8. Prototypes installed in the test cell (a), PCMs partially melted in the lower glazing (b) and different transmittance of the thermotropic layer (c).
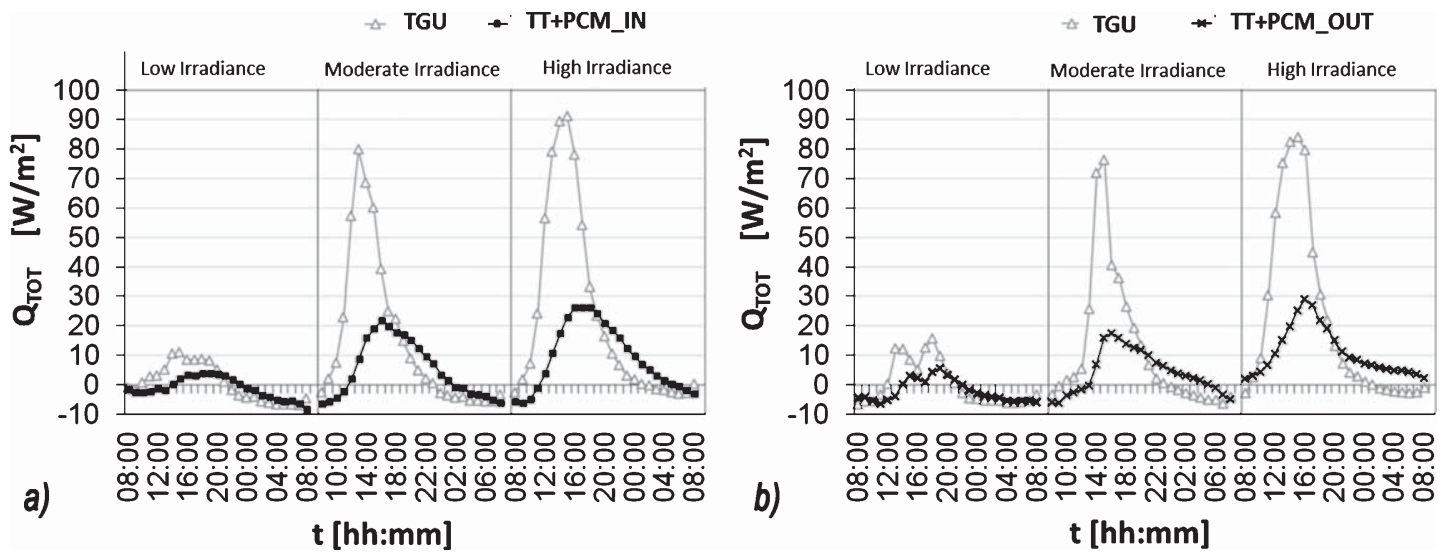

Fig. 9. Time profiles of specific 'surface' heat flux - TT+PCM_IN and reference (a) and TT+PCM_OUT and reference (b).

The time profiles of the specific 'total' heat flux exchanged by the glazing systems is shown in Figure 10. The different behaviours of the two TT+PCM configurations can be noticed, especially when high solar irradiance is present: while the configuration with the PCM in the innermost cavity is always able to reduce the total heat flux, regardless the boundary conditions, down to a maximum value of $35 \mathrm{~W} / \mathrm{m}^{2}$, the other configuration is only able to reduce the total heat flux down to a maximum value of approximately $70 \mathrm{~W} / \mathrm{m}^{2}$. This lower reduction, which is, nevertheless, relevant if compared with the reference technology (for which the total heat flux reaches almost $250 \mathrm{~W} / \mathrm{m}^{2}$ ), is due to the fact that, while in the first configuration PCMs do not complete the phase change, in the other one, due to the position of the PCM layer in the outermost cavity, the whole PCM layer melts and the latent heat of fusion is completely exploited.

The effect becomes more and more evident when the specific daily net energy $E_{24}$ is assessed. If compared to the reference technology (TGU), the configuration with the PCM in the innermost cavity (TT+PCM_IN) is able to reduce $E_{24}$ by $99 \%$, to $82 \%$, depending on the solar irradiance amount, while the configuration with the PCM in the outermost cavity (TT+PCM_OUT) shows a very similar 

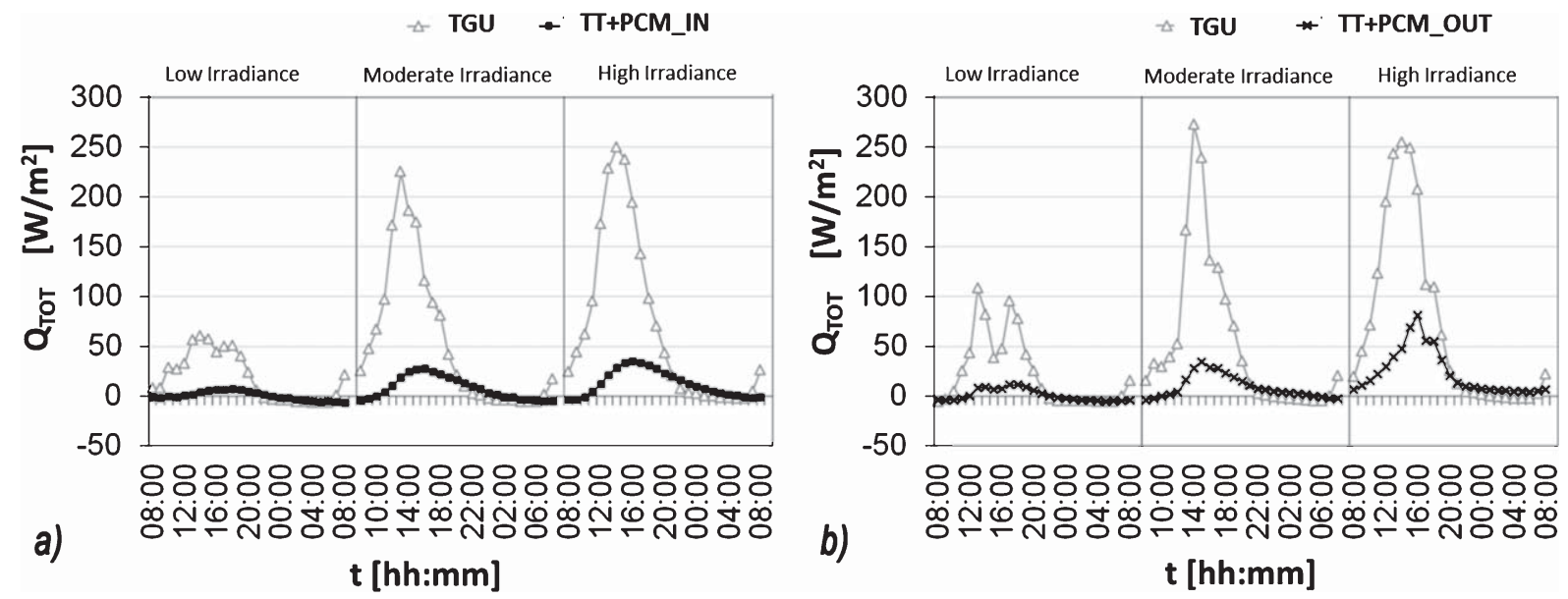

Fig. 10. Time profiles of total heat flux $-T T+P C M \_I N$ and reference (a) and TT+PCM_OUT and reference (b).

performance in case of low moderate irradiance, but when high solar irradiance is present (combined with high outdoor air temperatures) the reduction in $E_{24}$ is just $68 \%$. The different position of the PCM layer thus affects the thermo-physical behaviour of the system and makes one configuration more efficient than the other.

As far as the winter performance is concerned the obtained thermal transmittance for the TT+PCM system (assessed considering nocturnal value and PCMs in the solid state) and for the reference TGU shows that the insertion of the PCMs do not sensibly increase the heat transmittance of the glazing components, and a U-value of about $0.85 \mathrm{~W} / \mathrm{m}^{2}$ was found for all the glazing systems. As a drawback in the winter period the melting temperature of the tested PCMs (RT35HC), which were identified as the most appropriate for the cooling loads control, is too high to allow the phase change to occur thus limiting a full exploitation of solar heat gain entering the room.

The potential of this technology is quite high but the adoption of a PCM layer characterized by a single melting temperature considerably limits the dynamicity of the system and the responsiveness under different boundary conditions. Moreover the thermotropic layer shows a slightly translucent behaviour, even when in the off state, thus creating an unpleasant haze effect.

In order to overcome the main criticism some other strategies are currently under development, i.e. the adoption of electrochromic devices rather than the thermotropic glazing or polymeric layers to be used in the gap as a glazing spacer to allow for the coupling between two different PCMs.

\section{Conclusion}

The key role of the building envelope towards highly energy efficient building has been established for a long time. Nevertheless, until recent times, all efforts and attention have mainly been focused on increasing and optimizing the thermal insulation of the envelope components. This approach, in the forthcoming period dominated by Zero Energy Building (ZEB), reveals to be no more viable since, as the energy efficiency of the whole building is increasing, any further upgrade of building envelopes energy performance provides quite limited effects. 
New and more revolutionary concepts and technologies need to be developed at concept, system and material scale, working on the fact that the building envelope can play a key role in controlling the energy and mass flows from outdoors to indoors (and vice versa) and, moreover, the facades offer a significant opportunity for solar energy exploitation.

It appears necessary to switch from 'static' to 'responsive' and 'dynamic' systems, such as Multifunctional Facade Modules (MFMs) and Responsive Building Elements (RBE), identifying technological solutions able to continuously and pro-actively react to outdoor and indoor environment conditions and facilitate and enhance the exploitation of renewable and low exergy sources.

In this paper an overview of the technological evolution of the building envelope that has taken place, ranging from traditional components to the innovative skins, has been given, focusing on one hand on the different approaches that have characterized this development and, on the other hand, providing some examples of innovative solutions and highlighting the main potential and criticism resulting from an intensive experimental activity on this field.

\section{Acknowledgments}

Results presented in this paper are the main outcomes of a decennial activity on advanced building envelope components, carried out by the authors mainly in the framework of two research projects (SMARTGlass, Polight and PRIN-MIUR 2007). The authors are grateful to all the Ph.D. students involved in the research activity (Fabio Zanghirella, Francesco Goia, Lorenza Bianco, Ylenia Cascone, Fabio Favoino and Stefano Fantucci) and to all the technicians involved in the experimental set-up.

\section{References}

ASHRAE (2013). Handbook of Fundamentals, ASHRAE, 1791 Tullie Circle, Atlanta.

Bianco, L. (2014). Involucri Trasparenti Innovativi: Modellazione e sperimentazione su componenti dinamici e sistemi di facciata attivi. PhD Thesis, Turin, Italy.

Corgnati, S. P., Perino, M., \& Serra, V. (2007). Experimental assessment of the performance of an Active Transparent Façade during actual operating conditions, Solar Energy. Journal of the International Solar Energy Society, 81(8), 993-1013.

European Commission (2010). Directive 2010/31/EU of the European Parliament and of the Council of 19 May 2010 on the energy performance of buildings (recast). Official Journal of the European Union, 53, 13-35.

Favoino, F., Goia, F., Perino, M., \& Serra, V. (2012, May). Energy performance assessment of an advanced responsive multifunctional facade module: First results of an experimental campaign. Proceedings of the 5th International Building Physics Conference (IBPC 2012) (pp. 28-31). Kyoto, Japan.

Favoino, F., Goia, F., Perino, M., \& Serra, V. (2014a). Experimental assessment of the energy performance of an advanced responsive multifunctional façade module. Energy and Buildings, 68 (Part B), 647-659.

Favoino, F., Jin, Q., \& Overend, M. (2014b). Towards an Ideal Adaptive Glazed Façade for Office Building. Energy Procedia, 62, 289-298.

Favoino, F., Overend, M., \& Jin, Q. (2015). The optimal thermo-optical properties and energy saving potential of adaptive glazing technologies. Applied Energy, 156, 1-15.

Goia, F. (2013). Dynamic building envelope components and nearly zero energy buildings - theoretical and experimental analysis of concepts, systems and technologies for an adaptive building skin. PhD Thesis, Trondheim, Norway. Available in http://urn.kb.se/resolve? urn=urn:nbn:no:ntnu:diva-23867

Goia, F., Perino, M., Serra, V., \& Zanghirella, F. (2010). Towards an Active, Responsive and Solar Building Envelope. Journal of Green Building, College Publishing, 5(4), 121-136.

Goia, F., Haase, M., \& Perino, M. (2013). Optimizing the configuration of a façade module for office buildings by means of integrated thermal and lighting simulations in a total energy perspective. Applied Energy, 108.

Goia, F., Bianco, L., Cascone Y., Perino, M., \& Serra, V. (2014). Experimental Analysis of an Advanced Dynamic Glazing Prototype Integrating PCM and Thermotropic Layers. Energy Procedia, 48, 1272-1281.

Goia, F., Perino, M., \& Serra, V. (2014). Experimental analysis of the energy performance of a full-scale PCM glazing prototype. Solar Energy, $100,217-233$. 
Goia, F., Zinzi, M., Carnielo, E., \& Serra, V. (2015). Spectral and angular solar properties of a PCM-filled double glazing unit. Energy and Buildings, 87(1), 302-312.

Hottel, H. C. (1989). Fifty years of solar energy research supported by Cabot fund. Solar Energy, 43, 107-128.

Kasinalis, C., Loonen, R. C. G. M., Costola D., \& Hensen J. L. M. (2014). Framework for assessing the performance potential of seasonally adaptable facades using multi-objective optimization. Energy and Buildings, 79, 106-113.

Khunz, T. (1970). The Structure of Scientific Revolutions, The University of Chicago, Second Edition, enlarged, USA.

Loonen, R. C. G. M., Singaravel S., Trčka, M., Cóstola D., \& Hensen J. L. M. (2014). Simulation-based support for product development of innovative building envelope components. Automation in Construction, 45, 86-95.

Perino, M., \& Serra, V. (2011). L'innovazione dell'involucro trasparente: Oltre il concetto di isolamento termico, $48^{\circ}$ Congresso Internazionale AICARR - 'Il Recupero Energetico degli Edifici Esistenti: Quali Soluzioni per un Sistema Integrato, I'Involucro, gli Impianti e la Regolazione', Atti $48^{\circ}$ Convegno Internazionale AICARR (pp. 61-79).

Quesada, G., Rousse, D., Dutil, Y., Badache, M., \& Hallé, S. (2012a). A comprehensive review of solar facades. Opaque solar facades. Renewable and Sustainable Energy Reviews, 16, 2820-2832.

Quesada, G., Rousse, D., Dutil, Y., Badache, M., \& Hallé, S. (2012b). A comprehensive review of solar facades. Transparent and translucent solar facades. Renewable and Sustainable Energy Reviews, 16, 2643-2651.

Saadatian, O., Sopian, K., Lim, C. H., Asim, N., \& Sulaiman, M. Y. (2012). Trombe walls: A review of opportunities and challenges in research and development. Renewable and Sustainable Energy Reviews, 16, 6340-6351.

Samuelson, P. A., \& Nordhaus, W. D. (2001). Microeconomics (17th ed.). McGraw-Hill.

Serra, V., Zanghirella, F., \& Perino, M. (2010). Experimental evaluation of a climate façade: Energy efficiency and thermal comfort performance. Energy and Buildings, 42, 50-62.

Shepard, R. W. (1974). The law of diminishing returns. Lecture notes in economics and mathematical systems, 99, 287-318.

Torcellini, P., Pless, S. D., Judkoff, R., \& Crawley, D. (2007). Solar technologies and the building envelope. ASHRAE Journal, 14-22

UNI - EN 12831 (2006). Method for calculation of the design heat load, CEN and UNI standard.

Van der Aa, A. Heiselberg, P., \& Perino, M. (2011). Annex 44 - Final report - Designing with Responsive Building Elements. Aalborg: Aalborg University.

Xu, X., \& Dessel, V. (2008). Evaluation of a prototype active building envelope window-system. Energy and buildings, 40, 168-174

www.schueco.com/web/uk/unternehmen/presse/trade_fair_innovations/Schueco_E2_Facade_System_mature.

http://www.wicona-int.com/en/Product/Facade/TEmotion-Intelligent-facade-concept/ 